\title{
Excoriation (skin-picking) disorder: a systematic review of treatment options
}

This article was published in the following Dove Press journal:

Neuropsychiatric Disease and Treatment

14 July 2017

Number of times this article has been viewed

\section{Christine Lochner' \\ Annerine Roos' \\ Dan J Stein ${ }^{2}$}

'SU/UCT MRC Unit on Risk and Resilience in Mental Disorders, Department of Psychiatry, Stellenbosch University, South Africa; ${ }^{2} \mathrm{SU} / \mathrm{UCT}$ MRC Unit on Risk and Resilience in Mental Disorders, Department of Psychiatry and Mental Health, University of Cape Town, South Africa

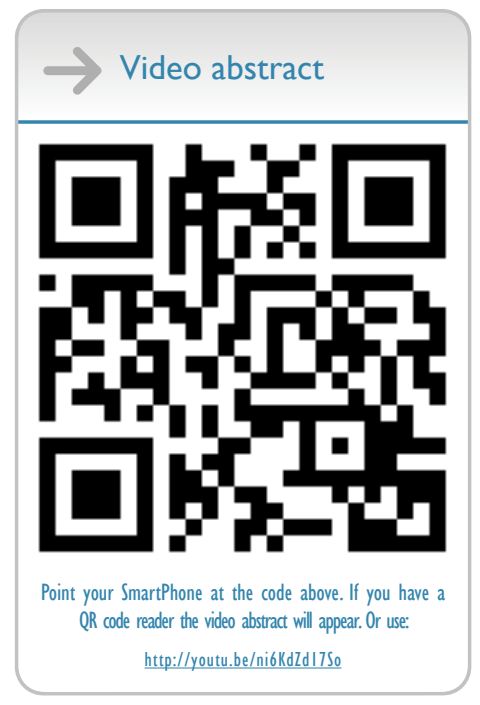

Correspondence: Christine Lochner SU/UCT MRC Unit on Risk and Resilience in Mental Disorders, Department of Psychiatry, Stellenbosch University, PO Box 24I, Cape Town 8000 , South Africa

$\mathrm{Tel}+27219389179$

Fax +27 21 9389738

Email cl2@sun.ac.za
Abstract: Although pathological skin-picking has been documented in the medical literature since the 19th century, it has only recently been included as a distinct entity in psychiatric classification systems. In the Diagnostic and Statistical Manual of Mental Disorders, 5th Edition and the proposed International Classification of Diseases, Eleventh Revision, excoriation (skin-picking) disorder (ED), also known as neurotic excoriation, psychogenic excoriation, or dermatillomania), is described as recurrent picking of skin, leading to skin lesions and significant distress or functional impairment. ED is listed as one of the obsessive-compulsive and related disorders, given its overlap with conditions such as trichotillomania (hair-pulling disorder). Arguably, its inclusion and delineation in the diagnostic nomenclature will lead to increased awareness of the condition, more research, and ultimately in treatment advances. This systematic review aims to provide readers with an up-to-date view of current treatment options for ED. A MEDLINE search of the ED treatment literature was conducted to collate relevant articles published between 1996 and 2017. The findings indicate that a number of randomized controlled trails on ED have now been published, and that current management options include behavioral therapy (habit reversal or acceptance-enhanced behavior therapy), and medication (selective serotonin reuptake inhibitors or $N$-acetyl cysteine).

Keywords: excoriation, skin-picking, treatment, habit reversal therapy, behavioral therapy, pharmacotherapy, systematic review

\section{Background}

Excoriation (skin-picking) disorder (ED), also known as dermatillomania, psychogenic excoriation, or neurotic excoriation, is characterized by recurrent picking of skin, leading to skin lesions and significant distress or functional impairment. ${ }^{1}$ Although documented in the medical literature since the 19 th century, ${ }^{2}$ ED has only recently been included as a distinct entity in mainstream psychiatric nosology. In the Diagnostic and Statistical Manual of Mental Disorders, 5th Edition (DSM-5) and the proposed International Classification of Diseases, Eleventh Revision (ICD-11), ED is listed as one of the obsessive-compulsive and related disorders (OCRDs), given its overlap with conditions such as trichotillomania (TTM or hair-pulling disorder).

Arguably, the inclusion and delineation of ED in the updated diagnostic nomenclature will give impetus to increased recognition of this condition. Skin-picking is quite common, with prevalence estimates of ED ranging between $1.4 \%$ and $5.4 \% .{ }^{3,4}$ ED may occur at any age, but it generally has its onset in adolescence, typically coinciding with the onset of puberty. ${ }^{5}$ The majority of individuals seeking treatment for ED are female. ${ }^{6}$ Dermatological conditions such as acne or eczema often trigger the onset of ED. Skin-picking triggers can be multiple, and may vary across individuals, but include emotions such as stress, anger, and anxiety, sedentary activities such as 
watching television and reading, and boredom and feeling tired. ${ }^{7-9}$ Skin-picking may be from any area of the body, and usually occurs in multiple sites, most commonly in the face, followed by the hands, fingers, arms, and legs. Healthy skin and minor skin irregularities are also picked.

An inability to stop picking despite repeated efforts to do so is typical ${ }^{10}$ and may lead to shame, anxiety, and depression. Indeed, the clinical impact of the disorder should not be underestimated; individuals with ED often spend a significant amount of time on repetitive picking and/or camouflaging (adding up to several hours per day in severe cases), leading them to miss or be late for work, school, or social activities. ${ }^{11}$ Different psychosocial sequelae, such as social embarrassment, avoidance of situations or activities where skin lesions can be detected, and loss of productivity in multiple settings, have also been reported. ${ }^{12}$ Possible medical sequelae include infections, lesions, scarring, and even serious physical disfigurement. ${ }^{13} \mathrm{ED}$ is also associated with substantial comorbidity including other body-focused repetitive behavior disorders - with TTM being the most common. Obsessive-compulsive disorder (OCD) and body dysmorphic disorder (BDD) are more prevalent in individuals with ED than in the general population. Mood and anxiety disorders are also common in ED. Cases have been documented where there was an increased risk of mortality. ${ }^{14,15}$

The severity of skin-picking ranges from mild to severe; in subclinical cases, intervention may not be needed, whereas when diagnostic criteria for ED are met, treatment is indicated. However, individuals with ED may not commonly seek treatment for their condition. ${ }^{16}$ It has been suggested that less than a fifth of patients seek treatment for their skin-picking. ${ }^{11}$ Reasons for not seeking help are, among others, social embarrassment, the belief that the condition is just a "bad habit", or that it is untreatable. ${ }^{2}$ Those who do seek treatment often present to a general practitioner or to a dermatologist before consulting a psychiatrist or a psychologist. ${ }^{2}$

In terms of treatment, there is a paucity of data. Nevertheless, management currently relies on a comprehensive psychiatric examination, behavioral therapy, and medication. This systematic review aims to provide readers with an upto-date view of treatment options for ED.

\section{Methods}

A MEDLINE search via the PubMed interface of ED treatment literature was conducted to collate relevant articles. Key search terms such as "excoriation disorder", "skin-picking disorder", "dermatillomania" and combinations thereof with "treatment", "pharmacotherapy", "medication", and "psychotherapy", with the use of the Boolean operators "and" or "or", were used to identify relevant empirical studies and reports. In this review, we focused on randomized controlled studies, uncontrolled studies, meta-analyses, and systematic reviews published between 1996 and 2017. The search was limited to the literature in the English language. Publications on pathological skin-picking occurring in the context of another mental disorder (eg, BDD), substance use (eg, cocaine), or another medical condition (eg, scabies or Prader-Willi syndrome) were not included.

\section{Results \\ Nonpharmacological treatment}

A significant benefit for nonpharmacological treatments, such as cognitive-behavioral therapy (CBT) and habit reversal therapy (HRT), in ED has been suggested. ${ }^{17,18}$

\section{Cognitive-behavioral interventions}

In the context of ED, CBT generally involves psychoeducation, cognitive restructuring, and an emphasis on relapse prevention through enhancement of self-efficacy, as well as agreement on clearly defined measures to prevent or address relapse. It also includes behavioral interventions such as HRT which has previously been used to treat a variety of repetitive behavior problems such as cheek biting, oral-digital habits, and $\mathrm{TTM}^{19}$ and which entails awareness training and competing response training. Awareness training includes elements such as self-monitoring. In competing response training, the patient is taught how to substitute skin-picking with an incompatible action (eg, fist clenching). Including these these elements of HRT, a 4-week randomized controlled trial (RCT) for ED ( $n=34)$ demonstrated efficacy, with treatment effects maintained at 2-month follow-up. ${ }^{20}$ Another small controlled study suggested that patients with ED $(n=19)$ treated with HRT over 3 sessions reported a greater decrease in skin-picking at post-treatment and follow-up compared to waiting list controls. ${ }^{21}$

Cognitive-behavioral interventions for ED may also be useful when presented in a self-help format that patients access themselves. Two studies to date have investigated the efficacy of such self-help interventions. The first, an uncontrolled study lasting $\sim 3$ months, investigated the efficacy of an Internet-based self-help treatment derived from the evidence-based cognitive-behavioral model of ED, in 151 patients. $^{22}$ Results revealed significant reductions in symptom severity ratings from baseline to post-intervention, suggesting that this approach is worth further study and may provide an alternative or adjunctive treatment for ED. The second trial was a randomized controlled study that compared 
HRT with decoupling (DC) - where the patient is taught how to "unlearn" picking (by replacing the skin-picking by a harmless behavior that mimics the central movements of the problematic behavior [eg, hand approaches the face where skin is picked]), but which then deviates to a different location where picking does not occur (eg, the ear). This deviation constitutes the start of a new behavioral sequence that ends in a harmless action (decoupling). Here, both treatments were delivered using bibliotherapy over 4 weeks (also via the Internet). The results confirmed the efficacy of self-help HRT for ED but were less supportive for the use of $\mathrm{DC}$ in ED. ${ }^{23}$

Acceptance and Commitment Therapy (ACT), which entails acceptance and mindfulness strategies, as well as commitment and behavior change strategies, has also been investigated in ED. This type of CBT promotes the acceptance of negative thoughts and feelings as part of the human experience ("acceptance") and encourages thinking of ways to respond to these negative thoughts and emotions in a way that is congruent with personal values and goals ("commitment") and not to engage in destructive behaviors such as skin-picking. In a preliminary study of five patients with ED, ACT led to a near complete cessation of skin-picking in four participants, but gains were not fully maintained in three of the four participants at follow-up. ${ }^{24}$ In another small pilot study that examined the utility of a combination of ACT and HRT (also known as acceptanceenhanced behavior therapy) for patients with TTM or ED, it was suggested that both these interventions greatly reduced pulling/picking for all participants $(n=5)$ and that the order in which ACT and HRT were implemented made little or no difference in the short-term treatment outcome. ${ }^{25}$ Meta-analysis supports the benefits of these interventions in ED. ${ }^{18}$

\section{Pharmacotherapy}

In the last decade or two, the efficacy and tolerability of a number of pharmacological agents have been tested in ED, with studies including selective serotonin reuptake inhibitors (SSRIs), lamotrigine, glutamatergic agents such as $\mathrm{N}$-acetyl cysteine (NAC) and riluzole, and opioid antagonists such as naltrexone. Augmentation strategies have also been investigated.

\section{Selective serotonin reuptake inhibitors}

A number of SSRIs have demonstrated improvement on measures of skin-picking behavior in ED. ${ }^{2}$ Nevertheless, study methods, including outcome measures, have varied. There have been two trials of fluoxetine (one an RCT and the other open-label), with both using a flexible dosing schedule up to either $80 \mathrm{mg}$ /day over 10 weeks $^{26}$ or $60 \mathrm{mg}$ /day over 6 weeks, ${ }^{27}$ respectively. The RCT suggested that fluoxetine improved symptoms significantly more than placebo, at a mean dosage of $55 \mathrm{mg} /$ day; however, this improvement was supported by only one of the three outcome measures used. ${ }^{26}$ In the second fluoxetine study, 6 weeks of open-label fluoxetine was prescribed, followed by a 6-week double-blind discontinuation phase for responders. About half (53.3\%) of the participants in the first open-label treatment phase were responders. Responders who were randomized to fluoxetine maintained their improvement during the double-blind discontinuation phase, whereas those on placebo returned to previous levels of picking severity. ${ }^{27}$ Some case reports also provide support for the use of fluoxetine in ED. ${ }^{28}$

One of the largest double-blind RCTs of an SSRI in ED to date $(n=45)$ found some support for the efficacy of citalopram (20 mg/day, over 4 weeks). ${ }^{29}$ Here, the total score on the Yale-Brown Obsessive-Compulsive Scale decreased significantly more with citalopram than with placebo. However, no significant differences were observed between the citalopram and placebo groups in terms of the primary outcome measure (a visual analogue scale).

An open-label trial of escitalopram, with a flexible dosing schedule of up to $30 \mathrm{mg}$ /day over 18 weeks, suggested that this agent may also be efficacious in reducing pathological skin-picking. ${ }^{30}$ In this trial $(\mathrm{n}=29)$, almost half of the sample $(44.8 \%)$ showed full remission of picking symptoms, with an additional $27.6 \%$ showing partial response. Significant main treatment effects were observed for all ED measures used. Another uncontrolled study using fluvoxamine, with a flexible dose range of $25-50 \mathrm{mg} /$ day to a maximum total dose of $300 \mathrm{mg}$ /day over a period of 12 weeks, reported that all participants (14/14) had a significant reduction in behaviors involving the skin (eg, scratching, picking, gouging, or squeezing), increased control over skin behavior, and a significant improvement in the presence of skin sensations, skin appearance, and lesions. ${ }^{31}$ Sertraline, at flexible dose, using a flexible study timeline in another open-label trial, has also showed promise as an SSRI that can reduce skin-picking $\left(68 \%\right.$ response rate) ${ }^{32}$

\section{Lamotrigine}

Data on the efficacy of lamotrigine (an anti-epileptic agent) in ED are inconsistent. To date, there have been two trials of lamotrigine in ED, both following a flexible dosing schedule over 12 weeks. ${ }^{16,33}$ The first, an open-label trial $(n=16),{ }^{16}$ found a $67 \%$ response rate, suggesting some benefit for this agent in 
ED. The second, a RCT $(n=7),{ }^{33}$ had a response rate of $43.8 \%$, thus failing to demonstrate greater benefit than placebo.

\section{Glutamatergic agents}

There is growing interest in the use of glutamatergic agents in OCD, TTM, and other OCRDs. ${ }^{2,34,35}$ Glutamate is a key excitatory central nervous system (CNS) neurotransmitter, and the glutamatergic system has been targeted for pharmacologic manipulation in OCRDs. NAC, for example, is a nutraceutical agent that modulates the glutamatergic and neuroinflammatory systems. The potential benefit of NAC in ED has been suggested by case reports. ${ }^{36}$ In addition, a recent randomized, double-blind trial (dosing range 1,200-3,000 mg/d) over 12 weeks found that NAC significantly reduced symptoms of ED. ${ }^{37}$ Almost half of the sample (15/32, 47\%) receiving NAC were much or very much improved compared to $19 \%(4 / 21)$ of participants receiving placebo. There were, however, no significant differences in psychosocial functioning between the active and placebo trial arms. There also is anecdotal evidence for the efficacy of the glutamate-modulating agent riluzole in reducing skin-picking. ${ }^{38}$

\section{Opioid antagonists}

In acral lick dermatitis, a condition found in dogs and that constitutes a possible animal model of ED, a role for opioid antagonists such as naltrexone has been suggested. ${ }^{39,40}$ In humans with ED, the efficacy of opioid antagonists is supported by case reports only. ${ }^{41}$

\section{Inositol}

Inositol, an isomer of glucose that has traditionally been considered a B vitamin, is another neutraceutical intervention that may be of use in ED; to date, there has been only one published uncontrolled study $(n=3)$ that showed reduced picking at 16 weeks post follow-up. ${ }^{42}$ The mechanism by which this agent exerts its therapeutic effects remains to be elucidated, but it is possibly linked to a modulatory effect on 5-HT transporter activity.

\section{Augmentation strategies}

To our knowledge, there have been no RCTs to investigate the efficacy of augmentation strategies in ED. However, a number of case studies have provided support for augmentation with atypical and typical antipsychotic agents in reducing skin-picking. For example, addition of aripiprazole to the serotonin-norepinephrine reuptake inhibitor venlafaxine (the latter prescribed for anxiety and depression) ended picking in one case of treatment-resistant ED. ${ }^{43}$ In two other cases, fluoxetine was augmented with olanzapine ${ }^{44}$ or paliperidone, ${ }^{45}$ resulting in reduced picking. Furthermore, case studies also support augmentation of SSRIs with typical antipsychotic agents such as haloperidol in ED. ${ }^{46}$

\section{Alternative interventions}

Alternative treatments, such as yoga, aerobic exercise, acupuncture, and hypnosis, either as monotherapy or as an adjunct to psychotherapy and/or pharmacotherapy, have been proposed for the treatment of ED. ${ }^{47}$ However, no RCTs with these modalities have been undertaken.

\section{Combined treatment}

To our knowledge, there are no rigorous studies that have investigated the efficacy of combinations of psychotherapy and pharmacotherapy in ED yet.

\section{Conclusion}

ED is often a chronic disorder associated with substantial morbidity and comorbidity. Fortunately, a number of treatment modalities are effective in reducing skin-picking behaviors. The literature systematically reviewed here, and previous meta-analyses, emphasize the relatively sparse evidence base, but also point to the benefit of behavioral treatments. ${ }^{17,18}$ SSRIs have been a mainstay of pharmacotherapy, but there is now evidence from a RCT that NAC should also be considered as a potential intervention. There is a need for consensus on the optimal symptom severity measures, and for additional controlled trials, using both explanatory and pragmatic designs. In the interim, there is also a need to improve accessibility to efficacious treatments.

\section{Acknowledgments}

The authors are supported by the South African Medical Research Council.

\section{Disclosure}

Dr Stein has received research grants and/or consultancy honoraria from Abbott, AstraZeneca, Eli-Lilly, GlaxoSmithKline, Jazz Pharmaceuticals, Johnson \& Johnson, Lundbeck, Orion, Pfizer, Pharmacia, Roche, Servier, Solvay, Sumitomo, Takeda, Tikvah, and Wyeth. The other authors report no conflicts of interest in this work.

\section{References}

1. American Psychiatric Association. Diagnostic and Statistical Manual of Mental Disorders (DSM-5). Washington DC: American Psychiatric Association; 2013.

2. Grant JE, Odlaug BL, Chamberlain SR, Keuthen NJ, Lochner C, Stein DJ. Skin picking disorder. Am J Psychiatry. 2012;169(11):1143-1149.

3. Hayes SL, Storch EA, Berlanga L. Skin picking behaviors: an examination of the prevalence and severity in a community sample. $J$ Anxiety Disord. 2009;23(3):314-319. 
4. Keuthen NJ, Koran LM, Aboujaoude E, Large MD, Serpe RT. The prevalence of pathologic skin picking in US adults. Compr Psychiatry. 2010;51(2):183-186.

5. Odlaug BL, Grant JE. Phenomenology and epidemiology of pathological skin picking. In: Grant JE, Potenza MN, editors. The Oxford Library of Psychology: Oxford Handbook of Impulse Control Disorders. New York, USA: Oxford University Press, 2011:186-195.

6. Bohne A, Keuthen N, Wilhelm S. Pathologic hairpulling, skin picking, and nail biting. Ann Clin Psychiatry. 2005;17(4):227-232.

7. Arnold LM, Auchenbach MB, McElroy SL. Psychogenic excoriation. Clinical features, proposed diagnostic criteria, epidemiology and approaches to treatment. CNS Drugs. 2001;15(5):351-359.

8. Neziroglu F, Rabinowitz D, Breytman A, Jacofsky M. Skin picking phenomenology and severity comparison. Prim Care Companion J Clin Psychiatry. 2008;10(4):306-312.

9. Snorrason I, Smari J, Olafsson RP. Emotion regulation in pathological skin picking: findings from a non-treatment seeking sample. $J$ Behav Ther Exp Psychiatry. 2010;41(3):238-245.

10. Lochner C, Grant JE, Odlaug BL, Stein DJ. DSM-5 field survey: skin picking disorder. Ann Clin Psychiatry. 2012;24(4):300-304.

11. Flessner CA, Woods DW. Phenomenological characteristics, social problems, and the economic impact associated with chronic skin picking. Behav Modif. 2006;30(6):944-963.

12. Stein DJ, Lochner C. Obsessive-compulsive and related disorders In: Sadock BJ, Sadock VA, Ruiz P, editors. Comprehensive Textbook of Psychiatry. Philadelphia, PA: Wolters Kluwer; 2017.

13. Odlaug BL, Grant JE. Clinical characteristics and medical complications of pathologic skin picking. Gen Hosp Psychiatry. 2008;30(1): $61-66$.

14. Kondziolka D, Hudak R. Management of obsessive-compulsive disorderrelated skin picking with gamma knife radiosurgical anterior capsulotomies: a case report. J Clin Psychiatry. 2008;69(8):1337-1340.

15. O'Sullivan RL, Phillips KA, Keuthen NJ, Wilhelm S. Near-fatal skin picking from delusional body dysmorphic disorder responsive to fluvoxamine. Psychosomatics. 1999;40(1):79-81.

16. Grant JE, Odlaug BL, Kim SW. Lamotrigine treatment of pathologic skin picking: an open-label study. J Clin Psychiatry. 2007;68(9): 1384-1391.

17. Schumer MC, Bartley CA, Bloch MH. Systematic review of pharmacological and behavioral treatments for skin picking disorder. J Clin Psychopharmacol. 2016;36(2):147-152.

18. Selles RR, McGuire JF, Small BJ, Storch EA. A systematic review and meta-analysis of psychiatric treatments for excoriation (skin-picking) disorder. Gen Hosp Psychiatry. 2016;41:29-37.

19. Miltenberger RG, Fuqua RW, Woods DW. Applying behavior analysis to clinical problems: review and analysis of habit reversal. J Appl Behav Anal. 1998;31(3):447-469.

20. Schuck K, Keijsers GP, Rinck M. The effects of brief cognitivebehaviour therapy for pathological skin picking: a randomized comparison to wait-list control. Behav Res Ther. 2011;49(1):11-17.

21. Teng EJ, Woods DW, Twohig MP. Habit reversal as a treatment for chronic skin picking: a pilot investigation. Behav Modif. 2006;30(4): 411-422.

22. Flessner CA, Mouton-Odum S, Stocker AJ, Keuthen NJ. StopPicking. com: internet-based treatment for self-injurious skin picking. Dermatol Online J. 2007;13(4):3.

23. Moritz S, Fricke S, Treszl A, Wittekind CE. Do it yourself! Evaluation of self-help habit reversal training versus decoupling in pathological skin picking: a pilot study. J Obsessive Compuls Relat Disord. 2012;1:41-47.

24. Twohig MP, Hayes SC, Masuda A. A preliminary investigation of acceptance and commitment therapy as a treatment for chronic skin picking. Behav Res Ther. 2006;44(10):1513-1522.

25. Flessner CA, Busch AM, Heideman PW, Woods DW. Acceptanceenhanced behavior therapy (AEBT) for trichotillomania and chronic skin picking: exploring the effects of component sequencing. Behav Modif. 2008;32(5):579-594.
26. Simeon D, Stein DJ, Gross S, Islam N, Schmeidler J, Hollander E. A double-blind trial of fluoxetine in pathologic skin picking. $J$ Clin Psychiatry. 1997:58(8):341-347.

27. Bloch MR, Elliott M, Thompson H, Koran LM. Fluoxetine in pathologic skin-picking: open-label and double-blind results. Psychosomatics. 2001;42:314-319.

28. Sharma H. Psychogenic excoriation responding to fluoxetine: a case report. J Indian Med Assoc. 2008;106:245-262.

29. Arbabi M, Farnia V, Balighi K, et al. Efficacy of citalopram in treatment of pathological skin picking: a randomized double blind placebo controlled trial. Acta Med Iran. 2008;46(5):367-372.

30. Keuthen NJ, Jameson M, Loh R, Deckersbach T, Wilhelm S, Dougherty DD. Open-label escitalopram treatment for pathological skin picking. Int Clin Psychopharmacol. 2007;22(5):268-274.

31. Arnold LM, Mutasim DF, Dwight MM, Lamerson CL, Morris EM, McElroy SL. An open clinical trial of fluvoxamine treatment of psychogenic excoriation. J Clin Psychopharmacol. 1999;19(1):15-18.

32. Kalivas J, Kalivas L, Gilman D, Hayden CT. Sertraline in the treatment of neurotic excoriations and related disorders. Arch Dermatol. 1996; 132(5):589-590.

33. Grant JE, Odlaug BL, Chamberlain SR, Kim SW. A double-blind, placebo-controlled trial of lamotrigine for pathological skin picking: treatment efficacy and neurocognitive predictors of response. $J$ Clin Psychopharmacol. 2010;30(4):396-403.

34. Grados MA, Atkins EB, Kovacikova GI, McVicar E. A selective review of glutamate pharmacological therapy in obsessive-compulsive and related disorders. Psychol Res Behav Manag. 2015;8:115-131.

35. Grant JE, Odlaug BL, Kim SW. N-acetylcysteine, a glutamate modulator, in the treatment of trichotillomania: a double-blind, placebocontrolled study. Arch Gen Psychiatry. 2009;66(7):756-763.

36. Odlaug BL, Grant JE. N-acetyl cysteine in the treatment of grooming disorders. J Clin Psychopharmacol. 2007;27(2):227-229.

37. Grant JE, Chamberlain SR, Redden SA, Leppink EW, Odlaug BL, Kim SW. N-Acetylcysteine in the treatment of excoriation disorder: a randomized clinical trial. JAMA Psychiatry. 2016;73(5):490-496.

38. Sasso DA, Kalanithi PS, Trueblood KV, et al. Beneficial effects of the glutamate-modulating agent riluzole on disordered eating and pathological skin-picking behaviors. J Clin Psychopharmacol. 2006; 26(6):685-687.

39. Dodman NH, Shuster L, White SD, Court MH, Parker D, Dixon R. Use of narcotic antagonists to modify stereotypic self-licking, self-chewing, and scratching behavior in dogs. $J$ Am Vet Med Assoc. 1988;193(7): 815-819.

40. White SD. Naltrexone for treatment of acral lick dermatitis in dogs. J Am Vet Med Assoc. 1990;196(7):1073-1076.

41. Piquet-Pessoa M, Fontenelle LF. Opioid antagonists in broadly defined behavioral addictions: a narrative review. Expert Opin Pharmacother. 2016;17(6):835-844.

42. Seedat S, Stein DJ, Harvey BH. Inositol in the treatment of trichotillomania and compulsive skin picking. J Clin Psychiatry. 2001;62(1): $60-61$.

43. Turner GA, Sutton S, Sharma A. Augmentation of venlafaxine with aripiprazole in a case of treatment-resistant excoriation disorder. Innov Clin Neurosci. 2014;11(1-2):29-31.

44. Christensen RC. Olanzapine augmentation of fluoxetine in the treatment of pathological skin picking. Can J Psychiatry. 2004;49(11): 788-789.

45. Spiegel DR, Finklea L. The recognition and treatment of pathological skin picking: a potential neurobiological underpinning of the efficacy of pharmacotherapy in impulse control disorders. Psychiatry (Edgmont). 2009;6(2):38-42.

46. Luca M, Vecchio C, Luca A, Calandra C. Haloperidol augmentation of fluvoxamine in skin picking disorder: a case report. J Med Case Rep. 2012;6:219.

47. Torales J, Barrios I, Villalba J. Alternative therapies for excoriation (skin picking) disorder: a brief update. Adv Mind Body Med. 2017; 31(1):10-13. 


\section{Publish your work in this journal}

Neuropsychiatric Disease and Treatment is an international, peerreviewed journal of clinical therapeutics and pharmacology focusing on concise rapid reporting of clinical or pre-clinical studies on a range of neuropsychiatric and neurological disorders. This journal is indexed on PubMed Central, the 'PsycINFO' database and CAS,

and is the official journal of The International Neuropsychiatric Association (INA). The manuscript management system is completely online and includes a very quick and fair peer-review system, which is all easy to use. Visit http://www.dovepress.com/testimonials.php to read real quotes from published authors.

Submit your manuscript here: http://www.dovepress.com/neuropsychiatric-disease-and-treatment-journal 